\title{
Random timing of elections and the political business cycle
}

\author{
VICTOR GINSBURGH
}

PHILIPPE MICHEL*

\begin{abstract}
In his 1975 paper, Nordhaus formally proves that governments whose aim is to be reelected, will generate 'political' business cycles. Empirical results do not confirm this proposition, especially in countries used to early elections.

We show that if there is a non-zero probability for elections to be called before the legal term, the political business cycle will be less pronounced, even if no early election actually takes place; moreover, if the normal electoral cycle is interrupted before the legal term, one might observe an inversion of the business cycle, or no cycle at all.
\end{abstract}

\section{Introduction}

In his 1975 paper, Nordhaus shows that if the ruling political party (or coalition) has a myopic ${ }^{1}$ vote maximizing behavior, and the economy is represented by a dynamic Phillips-curve, a purely political business cycle is generated, with high unemployment (and low inflation) during the period immediately following the election, and low unemployment (and high inflation) on the eve of the coming election.

This simplified model which does not include adjustment lags predicts that the unemployment rate must be falling over the entire period between two elections. Several authors, including Nordhaus himself, have tried to find some historical evidence of the theory. Nordhaus has shown that the theory holds in three of the nine countries studied, with strongest conformity for the United States. This is confirmed in a paper by McRae (1977). McCallum (1978), using a different set of statistical tests, disputes the conclusion and offers two alternative explanations: either, the successive U.S. administrations

\footnotetext{
* We are grateful to David Hendry for useful comments. At the European Public Choice Society Meeting in Oxford, April 1981, B. Frey made us aware of a paper by Lächler (1980), who used a similar approach to state and prove proposition 4.1

CORE, Université de Louvain; Université de Bruxelles, Belgium and Université de Paris I, France.
} 
simply have not used the unemployment-inflation trade-off or, the administrations cannot, even if they so desire, make use of the trade-off, in a world ruled by rational expectations.

Evidence is even less strong in most of the other democracies, as shown by Paldam (1979) who, though he deals only with cases in which governments remained in power throughout the normal election period - the most favorable case - finds a very weak cycle and no election-year effect in the data.

The main reason, usually given to explain these findings, is that governments have little and imperfect control over the business cycle, because of exogenous shocks, limited understanding among politicians of economic problems, various lags in the political system, etc. (see, e.g., Lindbeck, 1976).

A somewhat closer look at Nordhaus' empirical results may point to a different reason. Although, in theory, unemployment decreases over the entire cycle, Nordhaus tests the hypothesis that, for an electoral period of length $T$, the unemployment rate rises during the first $\frac{T}{2}$ years and falls during the remaining $\frac{T}{2}$ years. The test is performed on data between 1947 and 1972, in nine democracies. The results, reproduced in Table 1.1, are summarized by the probability $\pi$ 'that the number of successful theoretical predictions would have occurred by chance if the probability of a rise or fall is one half and independent' (Nordhaus, 1975: 186). The second line of Table 1.1 gives, for each country, the ratio of the number of early elections to that of total elections during the period 1947-48 to $1976-7 .^{2}$ This table gives strong support to the assumption that the political business cycle is more likely to appear or more likely to be detected or both, in countries like the F.R. of Germany, New Zealand and the United States where the electoral cycle is stable: more likely to appear, since politicians feel relatively sure of generating expansion in time, i.e., before a new election is called; more likely to be detected, since, if a new election is called before the legal term, the cycle, if it has been initiated, will usually be 'unfinished'.

Table 1.1. Conformity of history to theory

\begin{tabular}{|c|c|c|c|c|c|c|c|c|c|}
\hline & Australia & Canada & France & F.R. Germany & Japan & N. Zealand & Sweden & U.K. & U.S.A. \\
\hline \multirow{2}{*}{$\begin{array}{l}\text { Nordhaus' } \pi \\
\% \text { of early } \\
\text { elections }\end{array}$} & 0.70 & 0.87 & 0.25 & 0.09 & 0.70 & 0.03 & 0.39 & 0.62 & 0.01 \\
\hline & 0.45 & 0.45 & $0.40^{*}$ & 0.15 & 0.50 & 0.10 & 0.50 & 0.55 & 0.00 \\
\hline
\end{tabular}

* For France, early elections were frequent during the Fourth Republic; this was stopped by de Gaulle after 1958 . The given $\%$ is thus a weighted average, of 'before de Gaulle' $(0.60)$ and 'after de Gaulle' years $(0.20)$. 
The subject of this paper is to show that such data are consistent with the theoretical implications of a model identical to that considered by Nordhaus, except that the term of the next election is not known with certainty. Specifically, we show that, even if the real world behaved as naïvely as Nordhaus suggests

(a) there may be no business cycle or even an inversion of the cycle, if the election is called before the legal term;

(b) even if the term is the legal term, the business cycle is damped, when compared to the cycle generated under certainty; the 'cycle' always terminates with an expansionary effect preceding the new election, but there is no need for deflationary measures in the beginning of the cycle; in other words, the model does not predict monotonically decreasing unemployment over the period between two elections.

\section{The model}

Let $u_{t}$ and $\pi_{t}$ respectively represent the unemployment and inflation rates at time $t$ and assume, like Nordhaus, there exists an aggregate voting function $g\left(u_{t}, \pi_{t}\right)$ which depends only on current unemployment and inflation. Voters have a decaying memory, and the effect in $T$, the legal election date, of what happened at instant $t$ will be

$$
(1+\mu)^{t+1-T} g\left(u_{t}, \pi_{t}\right)
$$

where $\mu$ is the rate of decay of voters' memories. If the election term $T$ is known with certainty, the number of votes in $T$ will be

$$
\sum_{t=0}^{T-1}(1+\mu)^{t+1-T} g\left(u_{t}, \pi_{t}\right)
$$

The incumbent administration is assumed to steer the economy so as to maximize (2.1). The economy is formalized by a trade-off between prices and unemployment

$$
\pi_{t}=f\left(u_{t}\right)+\lambda v_{t} \quad t=0,1, \ldots, T-1
$$

and adaptive inflation rate expectations

$$
v_{t+1}-v_{t}=\gamma\left(\pi_{t}-v_{t}\right) \quad t=0,1, \ldots, T-1 .
$$

In (2.2) and (2.3), $v_{t}$ is the expected inflation rate. 
If the certainty assumption on the date of the election is dropped, the next election may take place at any instant $\theta(\theta=1,2, \ldots, T)$, and at the latest $T$. Let $R_{\theta}$ represent the event 'elections occur at time $\theta$ '; we will assume that the unique new element in the information set of the government at time $t$ is whether elections have been held by time $t$ or not. These events are

$$
F_{t}=\bigcup_{\tau=1}^{t} R_{\tau} \text { and } \bar{F}_{t}=\bigcup_{\tau=t+1}^{T} R_{\tau}
$$

In this case, the probability of election at time $\theta$, conditionally on 'elections have not been held by time $t, 0 \leqslant t<\theta \leqslant T^{\prime \prime}$ is

$$
p\left(R_{\theta} \mid \bar{F}_{t}\right)=p\left(R_{\theta}\right) / p\left(\bar{F}_{t}\right)
$$

$p\left(R_{\theta}\right)$ is the assessment made at time $t=0$ of the probability of election at time $\theta>0$. Clearly,

$$
p\left(R_{\theta}\right) \geqslant 0 ; \quad \sum_{\theta=1}^{T} p\left(R_{\theta}\right)=1 .
$$

Let also

$$
G\left(R_{\theta}\right)=\sum_{i=0}^{\theta-1}(1+\mu)^{t-\theta+1} g\left(u_{t}, \pi_{t}\right)
$$

be the number of votes cast for the incumbent if elections are held at time $\theta$. Then, the expected number of votes at time $t=0$ is

$$
\sum_{\theta=1}^{T} p\left(R_{\theta}\right) \sum_{t=0}^{\theta-1}(1+\mu)^{t-\theta+1} g\left(u_{t}, \pi_{t}\right)
$$

(2.5) is the stochastic equivalent of (2.1) and we will assume that the incumbent administration plans values $u_{t}(t=0,1, \ldots, T-1)$ which maximize (2.5), subject to (2.2) and (2.3).

If elections have not been held by time $\tau>0$, future decisions made at $t=\tau$, $\tau+1, \ldots, T-1$ will maximize

$$
\sum_{\theta=\tau+1}^{T} p\left(R_{\theta} \mid \bar{F}_{\tau}\right) \sum_{i=\tau}^{\theta-1}(1+\mu)^{t-\theta+1} g\left(u_{t}, \pi_{t}\right) .
$$

Hence, these decisions will also maximize (2.6) multiplied by the constant $p\left(\bar{F}_{\tau}\right)$, which is simply

$$
\sum_{\theta=\tau+1}^{T} p\left(R_{\theta}\right) \sum_{i=\tau}^{\theta-1}(1+\mu)^{t-\theta+1} g\left(u_{t}, \pi_{\tau}\right)
$$

(2.7) is the expected increase of votes resulting from decisions made between $\tau$ and $T$, if no election has been held by $\tau$. 
Consider a solution $u_{t}^{*}$ maximizing (2.5); set at $u_{t}^{*}$ all decisions $u_{t}$ and at $\pi_{t}^{*}$ the corresponding $\pi_{t}$ for $t \leqslant \tau-1$. The terms in (2.5) which are not set at their optimal values are those appearing in (2.7). The decisions which still have to be made, maximize (2.7). Hence the maximization of (2.5) defines a feedback optimal solution, in which the decision made at time $t$ is conditional on the past. $^{3}$

\section{The objective function under uncertainty}

In general, the probability of elections depends on other variables of the system, past and present: the Government may resign because of economic difficulties, or, like in the U.K., the Government may feel strong enough to call a new election. We deal here with the very simple case in which $p\left(R_{\theta}\right)$ is independent of $u_{t}$ and $\pi_{t}, t=0,1, \ldots, T-1{ }^{4}$

Anyway, this simplifying assumption is not as unrealistic as one may think. There are indeed many examples of Government which have had to step down for non-economic reasons. This has often been the case in France during the Fourth Republic, and Belgians would certainly not object to this view.

If $p\left(R_{\theta}\right)$ is independent of $u_{t}$ and $\pi_{t}$, we have the following equivalent expressions for (2.5):

$$
\begin{aligned}
& \sum_{\theta=1}^{T} \sum_{t=0}^{\theta-1}(1+\mu)^{t-\theta+1} p\left(R_{\theta}\right) g\left(\mu_{t}, \pi_{t}\right) \\
& =\sum_{t=0}^{T-1} \sum_{\theta=t+1}^{T}(1+\mu)^{t-\theta+1} p\left(R_{\theta}\right) g\left(u_{t}, \pi_{t}\right) \\
& =\sum_{t=0}^{T-1} p_{t} g\left(u_{t}, \pi_{t}\right)
\end{aligned}
$$

where

$$
p_{t}=\sum_{\theta=t+1}^{T}(1+\mu)^{t+1-\theta} p\left(R_{\theta}\right)
$$

is the weight on the future, of decisions made at time $t ; p_{t}$ is defined as a decaying sum of probabilities of elections occurring in $\theta>t$.

To compare (3.1) with the deterministic objective function

$$
\sum_{i=0}^{T-1}(1+\mu)^{t+1-T} g\left(u_{t}, \pi_{t}\right)
$$

define $q_{t}=(1+\mu)^{T-t-1} p_{t}$ and write (3.1) as

$$
\sum_{t=0}^{T-1}(1+\mu)^{t+1-T} q_{t} g\left(u_{t}, \pi_{t}\right)
$$


Consider the special case in which the probability to reach the legal term is $\delta$ and the probability of early elections at time $t \neq T$ is $\frac{1-\delta}{T-1}$. Thus

$$
\begin{aligned}
& p\left(R_{T}\right)=\delta \quad 0 \leqslant \delta \leqslant 1 \\
& p\left(R_{t}\right)=\frac{1-\delta}{T-1} \quad t=1,2, \ldots, T-1 .
\end{aligned}
$$

Using (3.2) and (3.5), it is readily checked that

$$
\begin{aligned}
& q_{T-1}=\delta \\
& q_{t} \quad=\delta+\frac{1-\delta}{T-1} \sum_{\theta=t+1}^{T-1}(1+\mu)^{T-\theta} \quad t=0,1, \ldots, T-2 .
\end{aligned}
$$

We state

Proposition 3.I: If early elections are equally probable for $t=1,2, \ldots, T-1$ (assumption 3.5) the cumulated effect on the objective function of the decaying memory is completely offset by the effect of a possible early election if $\delta<\widetilde{\delta}$, $\tilde{\delta}=\frac{1+\mu}{1+\mu T}$.

Proof: Using (3.6), we obtain

$$
q_{t}-(1+\mu) q_{t+1}=-\mu \delta+(1+\mu) \frac{1-\delta}{T-1}
$$

which is positive if and only if $\delta<\tilde{\delta}=\frac{1+\mu}{1+\mu T}$.

This inequality holds for very reasonable values of $\delta$. For the U.S., Nordhaus sets $\mu=0.03$. Since $T=4, \delta=0.92$; thus, even if the probability of an early election is small ( 0.03 in this case), the memory effect is reversed. Note also that this is always the case for $\delta=\frac{1}{T}$ which implies $p\left(R_{t}\right)=\frac{1}{T}$ $(t=1,2, \ldots, T)$.

The offsetting of the memory effect suggests that the political business cycle may be reversed. But in Nordhaus" model, the existence of the political business cycle results from the dynamic Phillips-curve: the cycle exists even if $\mu=0$. 


\section{Optimal government behavior under uncertainty}

The problem the Administration faces, is

$$
\max \sum_{t=0}^{T-1} p_{t} g\left(u_{t}, \pi_{t}\right)
$$

subject to

$$
\begin{aligned}
& \pi_{t}=f\left(u_{t}\right)+\lambda v_{t} \\
& v_{t+1}-v_{t}=\gamma\left(\pi_{t}-v_{t}\right)
\end{aligned} \quad t=0,1, \ldots, T-1 .
$$

Like Nordhaus, we adopt as preference function

$$
g\left(u_{t}, \pi_{t}\right)=C-u_{t}^{2}-\beta \pi_{t} \quad \pi_{t} \geqslant 0, \beta>0
$$

and

$$
f\left(u_{t}\right)=\alpha_{0}-\alpha_{1} u_{t}
$$

The model is then

$$
\max \sum_{t=0}^{T-1} p_{t}\left(C-u_{t}^{2}-\beta \alpha_{0}+\beta \alpha_{1} u_{\tau}-\beta \lambda v_{t}\right)
$$

subject to

$$
v_{t+1}-v_{t}=\gamma\left[\alpha_{0}-\alpha_{1} u_{t}-(1-\lambda) v_{t}\right]
$$

To solve this concave maximization problem, we set up a Lagrangean function

$$
\begin{aligned}
& \mathscr{L}(.)=\sum_{t=0}^{T-1} p_{t}\left(C-u_{t}^{2}-\beta \alpha_{0}+\beta \alpha_{1} u_{t}-\beta \lambda v_{t}\right) \\
& -\sum_{t=0}^{T-1} \psi_{t+1}\left[\gamma\left(\alpha_{0}-\alpha_{1} u_{t}+\lambda v_{t}-v_{t}\right)+v_{t}-v_{t+1}\right] .
\end{aligned}
$$

Define $1+r_{t}=p_{t} / p_{t-1}$ and $\phi_{t+1}=\psi_{t+1} / p_{t}$. The necessary conditions for a maximum are:

$$
\begin{array}{ll}
\phi_{T}=0 & \\
\phi_{t}=\beta \lambda\left(1+r_{t}\right)+(1+\gamma \lambda-\gamma)\left(1+r_{t}\right) \phi_{t+1} & t=1,2, \ldots, T-1 \\
u_{t}^{*}=\frac{\beta \alpha_{1}}{2}+\frac{\gamma \alpha_{1}}{2} \phi_{t+1} & t=0,1, \ldots, T-1 .
\end{array}
$$


Proposition 4.1: (a) If the actual (random) election date is the legal date $T, u_{0}^{*}$, the initial unemployment rate is always larger than $u_{T-1}^{*}$, the unemployment rate at the new election's eve. (b) If early elections are equally probable in $t$ $=1,2, \ldots, T-1$ (Assumption (3.5)) $u_{0}^{*}-u_{T-1}^{*}$ decreases when the probability of early elections (i.e., uncertainty) increases.

Proof: (4.3) and (4.4) imply $\phi_{t}>0$ for $t \leqslant T-1$. Hence $\phi_{1}>0$; since $\phi_{T}=0$, (4.5) shows that necessarily $u_{0}^{*}>u_{T-1}^{*}$, which proves part (a) of the proposition. To prove (b), note first that using (3.5), $p_{t}$ defined in (3.2) can be written

$$
\begin{aligned}
p_{t} & =\delta(1+\mu)^{t+1-T}+\frac{1-\delta}{T-1} \sum_{\theta=t+1}^{T-1}(1+\mu)^{t+1-\theta}= \\
& =\delta(1+\mu)^{t+1-T}+\frac{(1-\delta)(1+\mu)}{(T-1) \mu}\left[1-(1+\mu)^{t+1-T}\right]
\end{aligned}
$$

$p_{t}$ also verifies the recurrence relation

$$
p_{t}=p\left(R_{t+1}\right)+(1+\mu)^{-1} p_{t+1} \quad t=0,1, \ldots, T-1
$$

Hence

$$
\begin{aligned}
\frac{p_{t-1}}{p_{t}} & =\frac{p\left(R_{t}\right)}{p_{t}}+(1+\mu)^{-1} \\
& =\frac{1-\delta}{(T-1) p_{t}}+(1+\mu)^{-1} \cdot \quad t=1,2, \ldots, T-1
\end{aligned}
$$

From (4.6), it is seen that $(1-\delta) / p_{\imath}$ increases with increasing $(1-\delta)$; so does $p_{t-1} / p_{t}$ in (4.8). Hence $\frac{p_{t}}{p_{t-1}}=1+r_{t}$ decreases with increasing $(1-\delta)$; since all $1+r_{t}(t=0,1, \ldots, T-1)$ decrease, so do the $\phi_{t}{ }^{\text {'s. Finally }}-\frac{\partial \phi_{1}}{\partial \delta}<0$ and $-\frac{\partial\left(u_{0}^{*}-u_{T-1}^{*}\right)}{\partial \delta}<0$

We have shown that, even if the unemployment rate is not falling over the entire electoral cycle as in Nordhaus' case, nevertheless $\Delta u^{*}=u_{0}^{*}$ $-u_{T-1}^{*}>0$. But, the greater the probability of an early election, the smaller $\Delta u^{*}$, even if eventually the election date coincides with the legal date. This is consistent with Paldam's (1979) findings: even in the best case, i.e., when the Government remains in power for the whole of the normal election period, the business cycle is not strong.

However, if the election date is $\theta<T$, it may happen that $u_{0}^{*}-u_{\theta-1}^{*}<0$, implying that the cycle which is actually observed is inverted. 
Example: Using parameters given by Nordhaus (1975) and McRae (1977) we computed the optimal paths under four different assumptions; in all cases, the legal term $T$ is four years.

Assumption 1: Certainty Case. Elections are held exactly every four years: $p\left(R_{1}\right)=p\left(R_{2}\right)=p\left(R_{3}\right)=0 ; p\left(R_{4}\right)=1$.

Assumption 2: 'Equal' Uncertainty Case: Elections are equally probable every year: $p\left(R_{t}\right)=0.25, t=1, \ldots, 4$.

Assumption 3: Uncertainty Case $\mathrm{A}: p\left(R_{1}\right)=p\left(R_{4}\right)=0.45$ and $p\left(R_{2}\right)=p\left(R_{3}\right)$ $=0.05$; the election is however held at the legal date $T=4$.

Assumption 4: Uncertainty Case B: $p\left(R_{1}\right)=p\left(R_{4}\right)=0.45$ and $p\left(R_{2}\right)=p\left(R_{3}\right)$ $=0.05$; the Government falls after two years.

Results are compared in Table 5.1.

Table 5.1. Optimal unemployment paths under different assumptions on the timing of elections

\begin{tabular}{|c|c|c|c|c|c|c|c|c|}
\hline \multirow{3}{*}{ Period } & \multicolumn{8}{|c|}{ Optimal employment paths } \\
\hline & \multicolumn{2}{|c|}{$\begin{array}{l}\text { Assumption } 1 \\
\text { 'Certainty' }\end{array}$} & \multicolumn{2}{|c|}{$\begin{array}{l}\text { Assumption } 2 \\
\text { 'Equal } \\
\text { uncertainty' }\end{array}$} & \multicolumn{2}{|c|}{$\begin{array}{l}\text { Assumption } 3 \\
\text { 'Uncertainty A' }\end{array}$} & \multicolumn{2}{|c|}{$\begin{array}{l}\text { Assumption } 4 \\
\text { 'Uncertainty B' }\end{array}$} \\
\hline & $p()$. & $u$ & $p()$. & $u$ & $p()$. & u & $p()$. & $u$ \\
\hline 1 & 0 & 0.048 & 0.25 & 0.039 & 0.45 & 0.039 & 0.45 & 0.039 \\
\hline 2 & 0 & 0.043 & 0.25 & 0.036 & 0.05 & 0.041 & 0.05 & 0.041 \\
\hline 3 & 0 & 0.036 & 0.25 & 0.033 & 0.05 & 0.036 & $\ldots$ & $\ldots$ \\
\hline 4 & 1 & 0.030 & 0.25 & 0.030 & 0.45 & 0.030 & $\ldots$ & $\ldots$ \\
\hline
\end{tabular}

$p($.$) is the assessment made at time 0$ at the probability of election in years $t=1, \ldots, 4$. $u$ represents the unemployment rate.

It can be checked that when the term of the election is uncertain, even if no election is actually held before the legal term, the planned business cycle is much less pronounced than in the certainty alternative (compare Assumption 1 with Assumptions 2 and 3). Moreover, the cycle is not necessarily monotone as is seen for Uncertainty Case A. Furthermore, in Uncertainty Case B, we assume that the Government falls after two years, though it planned on remaining in power for four years, with some uncertainty; the cycle is reversed: instead of 'observing' large unemployment in the beginning and small unemployment on election's eve, we 'observe' the opposite situation. In general, under uncertainty the business cycle is damped and may thus be more difficult to trace from an empirical point of view, even when it exists. 


\section{NOTES}

1. By myopic, Nordhaus qualifies a behavior in which voters do not evaluate the post-election consequences of pre-election policies.

2. The data are based on Figure 2 in Paldam (1979).

3. These restrictive assumptions on the information set are not necessary to derive solutions. A more general case is considered in Ginsburgh and Michel (1980).

4. See Ginsburgh and Michel (1980) for a generalization.

4. All parameters are Nordhaus' except $\alpha_{1}=1.5$ which is McRae's. Nordhaus gives a value of 0.06 for $\alpha_{1} \beta$, so we set $\beta=0.04$. Other parameters are $\lambda=0.7, \gamma=0.3$ and $\mu=0.03$.

\section{REFERENCES}

Ginsburgh, V., and Michel, P. (1980). Random timing of elections and the political business cycle. CORE Discussion Paper 8043, November.

Lächler, U. (1980). Political business cycles in parliamentary democracies. University of Maryland Working Paper 8013.

Lindbeck, A. (1976). Stabilization policy in open economies with endogenous politicians. American Economic Review, Papers and Proceedings 66: 1-19.

McCallum, B. T. (1978). The political business cycle: An empirical test. Southern Economic Journal 44: 504-515. McRae, C. D. (1977). A political model of the business cycle. Journal of Political Economy 85:239-
263 .

Nordhaus, W.D.(1975). The political business cycle. The Review of Economic Studies 42: 169-190.

Paldam, M. (1979). Is there an electional cycle? A comparative study of national accounts. The Scandinavian Journal of Economics 81: 323-342. 